\title{
DEMOCRACIA QUE TEMOS/QUEREMOS, MEDIANTE O CONSERVADORISMO NAS POLÍTICAS EDUCACIONAIS
}

Francisca Pereira Salvino ${ }^{(*)}$

Lenilda Cordeiro de Macedo

O currículo de Pedagogia da Universidade Estadual da Paraíba (UEPB/campus I) passou por um processo de reconstrução de setembro 2014 a agosto de 2016, motivado por fatores externos e internos, tais como: mudanças nas demandas e políticas sociais e educacionais, locais e nacionais, as quais o curso necessitava se adequar; persistência e/ou agravamento de problemas educacionais; alteração do perfil de discentes e docentes de Educação Básica e Superior; término da vigência do Projeto Pedagógico do Curso (PPC), ${ }^{1}$ e mudanças nas opções teórico-metodológicas de docentes do curso, em parte fomentadas por estudos informais, doutorados, aposentadorias e ingresso de novos profissionais.

Essa reconstrução do PPC, portanto, também do currículo, segundo documentos do Núcleo Docente Estruturante (NDE), ${ }^{2}$ desenvolveu-se em várias etapas e atividades, a saber: mobilização e sensibilização de docentes e discentes; autoavaliação do curso, através da qual foram consultados/as 15 docentes e 306 discentes sobre o nível de satisfação com o curso, através de questionário (online); curso de extensão para sistematização dos dados da autoavaliação; reuniões; Seminário Nacional de Pedagogia (SENPED); assembleias e sistematização do texto. Tudo isso ocorreu concomitante ao processo de impeachment da ex-presidente Dilma Rousseff, concluído em 31/08/2016, que reacendeu debates e disputas em torno do significante democracia, fazendo ecoar, no Brasil e no exterior, narrativas acerca da legalidade e legitimidade do impeachment ou de sua configuração como "Golpe de Estado" ou "Estado de exceção". Nesse ínterim, foram recorrentes nos ambientes da Universidade manifestações, palestras, seminários, panfletagens, comunicação em redes sociais virtuais (Facebook e Whatsapp, principalmente) e outras atividades sobre a conjuntura nacional, que afetaram de diferentes modos o processo, os discursos e as identidades.

\footnotetext{
${ }^{(*)}$ Francisca Pereira Salvino. Doutora em Educação pela Universidade do Estado do Rio de Janeiro (UERJ) e professora do Departamento de Educação da Universidade Estadual da Paraíba (UEPB).

Lenilda Cordeiro de Macedo. Doutora em Educação Pela Universidade Federal da Paraíba (UFPB) e professora do Departamento de Educação da Universidade Estadual da Paraíba (UEPB).

${ }^{1}$ O PPC foi aprovado em 2009, mas a CONAES recomenda que os PPC sejam atualizados a cada 5 anos de vigência.

${ }^{2}$ Grupo formado por 5 professores eleitos para coordenar a reconstrução, implementação, acompanhamento e avaliação dos PPC, conforme recomendação da CONAES.
} 
Em sociedades mais complexas como a Brasileira, as relações entre local/ nacional/global, particular/universal, objetivo/subjetivo são melhor compreendidas sem a pretensão de intercetar os fluxos de comunicação, influência e interferência, uma vez que eles se hibridizam de tal forma que se torna impossível a existência de um sem o outro. Assim, a reconstrução do PPC, enquanto processo político, deve ser considerada em seu entrelaçamento com demandas e questões nacionais. Com esse entendimento, nós, que estávamos envolvidas nessas atividades e também do PPC, pudemos constatar o seguinte: discussões em torno dessa conjuntura foram inexistentes nas atividades especificamente voltadas à reconstrução do PPC; a mobilização dos/as estudantes para participação no PPC e exclusão destes/as nas etapas de tomada de decisão; a participação (militância) de docentes do Departamento de Educação nas atividades contra o impeachment; a "quase ausência" de discussão em torno dos temas e questões suscitados pela conjuntura nacional, uma vez que as atividades se configuraram como militância contra o impeachment; assim, argumentos em favor eram rechaçados e o falante adjetivado de "coxinha", golpista, ignorante. Portanto, admitia-se quase que exclusivamente, duas posições dos sujeitos: contrários ao impeachment e silenciados. Certamente, nenhum projeto institucional ou societário alcança uma condição democrática sem conflitos, via consenso apriorístico, concessão/autorização de dirigentes/governantes ou "conversão/doutrinação" de pessoas. Portanto, prescinde de debates de ideias, análises diferentes sobre o mesmo objeto e liberdade de expressão.

Esse estado de coisas na academia é demasiado importante, não apenas pelo momento de inflexão que a sociedade vivenciava; mas, sobretudo, porque a universidade deve ser, por excelência, espaço de desenvolvimento do pensamento crítico (entendido aqui não necessariamente como marxista ou de "esquerda"). Como afirma Santos (1995, p. 5), trata-se de "um pensamento hábil e responsável, que conduz à formação de juízos, porque se apoia em critérios, é autocorretivo e sensível ao contexto", possibilitando aos sujeitos decidir, posicionar-se e agir com certa liberdade e respeito ao "diferente".

Diante desse quadro, surgiram inquietações e o interesse em analisar o processo de reconstrução do currículo de Pedagogia (UEPB/campus I), enfatizando significados de democracia que o permearam. Orientamo-nos por duas indagações em especial: i) O que a comunidade entendia por democracia?; ii) A reconstrução do currículo de Pedagogia se constituiu em processo democrático?

$\mathrm{Na}$ busca de responder a essas questões, primeiramente optamos pelo método da observação participante, com recurso de questionário e análise de textos/documentos, incluindo mensagens de uma rede social virtual (Whatsapp), de modo a corroborar a recomposição dos sentidos de 
democracia que permearam o referido processo. Passando à análise, recorremos a estudos realizados por Laclau e Mouffe (2015), Fernandes Enguita (2013), Bauman (2000), dentre outros, a partir dos quais dialogamos sobre significados de democracia e currículo, enquanto construções/produções históricas, que influenciam na formação das identidades e são atravessadas por relações de poder assimétricas. Como asseveram Lopes e Macedo (2011), ao prescrever e legitimar conhecimentos válidos para serem ensinados e aprendidos e ao proporcionar experiências nesse sentido, o currículo nos governa, regula o que somos, o que nos tornamos. Todavia, o currículo também possibilita o desenvolvimento da capacidade crítica, que nos autoriza a pensar e agir com certo nível de liberdade, em função de uma sociedade mais justa, intercultural e democrática.

Além dessa introdução, o presente artigo compreende outras quatro seções, a saber: a primeira aborda significados de democracia e conservadorismo; a segunda aborda elementos progressistas e conservadores das políticas educacionais no Brasil a partir da década de 1990; a terceira situa o leitor quanto à metodologia, ao campo empírico e aos sujeitos da pesquisa; a quarta analisa o processo de reconstrução do PPC e do currículo de Pedagogia, enfatizando significados de democracia, expressos por docentes e discentes do curso; e a última traz nossas considerações finais.

\section{DEMOCRACIA E CONSERVADORISMO}

A ambiguidade, a polissemia e a dispersão de sentidos que envolve o significante democracia e as identidades do "sujeito da democracia" apontam para a precariedade e a ausência de sutura, que é marca em qualquer totalidade discursiva. Nessa perspectiva, Laclau e Mouffe (2015, p. 198) analisam que,

Devido a esta ausência de uma sutura final, a dispersão das posições de sujeito não pode constituir uma solução: dado que nenhuma delas consegue, em última instância, se consolidar como uma posição separada há um jogo de sobredeterminação entre elas que reintroduz o horizonte de uma totalidade impossível.

A necessidade/impossibilidade da sociedade, da democracia e da identidade democrática nos move em direção a horizontes incertos e fugidios, exigindo estratégias, articulações, negociações e arranjos políticos (mais ou menos duradouros) que apenas permitem uma fixação de sentidos provisória e contingente. Permitem instituir, através de decisões e práticas políticas, um dos modos possíveis de atender determinadas demandas da sociedade que, por convenção, podem ser nomeados de democracia ou de ditadura. Democracia, portanto, é entendida como um "significante 
vazio", que diferentes identidades particulares (indivíduos, partidos, sindicatos, agremiações, classes, mídias e outras) intentam preencher (LACLAU, 2011). Para isso, precisam abrir mão de características, interesses e ideologias particulares para se articularem em torno de um universal comum, que os oriente e dê sentido ao jogo político. Constroem-se, assim, política e historicamente, sentidos de democracia e de identidades democráticas que se tornam hegemônicos por determinado tempo, porém, sempre sujeitos a novas interpelações e ressignificações.

Em conformidade com essa compreensão, um dos significados possíveis de democracia surge a partir do declínio do feudalismo, dos estados monárquicos e da teologia e consolida-se com as sociedades urbano-industriais (capitalistas), com os Estados de direito (presidencialistas, parlamentaristas ou outros sistemas representativos) e com o liberalismo, que lhe dá sustentação. Vem do século XVIII, marcado pela Revolução Francesa (1789), pelos ideais republicanos da burguesia em ascensão (igualdade, propriedade, liberdade e fraternidade) e pelas lutas dos povos por condições dignas de trabalho e de sobrevivência. Nesse movimento, como analisa Fernandez Enguita (2013, p. 57),

O Estado-nação se converteu na forma moderna da pólis, e a escola, um dos seus principais instrumentos de produção e reprodução, e particularmente de sua legitimidade. O Estado moderno é a forma de comunidade política que se converteu em dominante frente a outras formas potenciais de organização das grandes coletividades.

A escolarização em massa e os currículos favoreceram uma nova sociabilidade para adaptação das pessoas ao modo de produção e à vida urbana; o desenvolvimento científico e tecnológico dinamizou os sistemas (produção, comércio, monetário, financeiro e fiscal), facilitou a mobilidade das pessoas (transportes) e as relações políticas e sociais (redes de comunicação físicas e virtuais). Também nesse contexto, o termo conservadorismo foi moldado na Inglaterra e na França, sendo o rótulo atribuído àqueles movimentos que, à época, eram revolucionários, por buscarem mudança política, social e cultural. Portanto, está ligado ao liberalismo, uma vez que defende a liberdade individual, a propriedade privada, uma menor interferência estatal na economia e na sociedade em geral. Na França do século XIX, por exemplo, os conservadores (alta burguesia) sentavam à direita no parlamento e os opositores (trabalhadores e pequena burguesia) à esquerda.

No século XX, pautando-se nesse modelo político-econômico, países da Europa, da América do Norte e de outros continentes, dentre os quais o Brasil, produziram riquezas em larga escala e benesses inquestionáveis no tocante às condições de vida das populações, à redução da mortalidade infantil e ao aumento da expectativa de vida, por exemplo. Simultaneamente, produziram mazelas, tais como: concentração de riquezas para poucos e de pobreza para muitos, entre as nações e no 
interior delas; exploração descontrolada e insustentável de recursos naturais; segregações e exclusões em função de diferenças econômicas, regionais e culturais; crescimento desordenado de centros urbanos e outras.

Quando as desigualdades e injustiças do capitalismo encetaram conflitos e guerras civis e mundiais, na Europa Oriental e da Ásia do século XX, fez emergir o socialismo e outro significado de democracia, formulados a partir do marxismo. Este preconizava uma economia planificada, distribuição igualitária das riquezas, extinção da propriedade privada, do mercado, da classe proprietária (capitalista), da religião, bem como apropriação das propriedades (terras, empresas, máquinas, dinheiro e outros) pelo Estado. Em o "Manifesto comunista", Marx e Engels (1999, p. 41) afirmam:

O proletariado utilizará sua supremacia para arrancar pouco a pouco todo capital à burguesia, para centralizar todos os instrumentos de produção nas mãos do Estado, isto é, do proletariado organizado em classe dominante, e para aumentar, o mais rapidamente possível, o total das forças produtivas.

Segundo os autores, o advento do proletariado como classe dominante seria a primeira fase da revolução socialista até alcançar o comunismo (sociedade/democracia plena). Eles advertiam que isto apenas seria possível pela violação despótica, já que a burguesia não renunciaria à dominação de bom grado; de forma diferente em cada país, a começar pelos países capitalistas mais adiantados.

Como entendem Laclau e Mouffe (2015), ao pretender elevar a classe operária em "universal", em classe em si, o socialismo produziu hegemonias autoritárias como a ditadura do proletariado e o stalinismo, que prometiam ser transitórias, mas das quais não conseguiu se desvencilhar e avançar para construção de hegemonias democráticas. Para se afirmar no poder, as soluções encontradas foram eliminar a classe opositora (alta burguesia) e seu aparato de dominação: ideologia, religião, família e outros, além de ampliar "a noção de classe", para incluir nesta o proletariado, o trabalhador do campo e a pequena burguesia. Essa solução gerou as categorias “massas” e “dirigentes”. Sobre esse aspecto, comentam Laclau e Mouffe (2015, p. 122):

Uma vez que toda relação política é concebida como uma relação de representação, um substitucionismo progressivo move-se da classe ao partido (representação dos interesses objetivos do proletariado) e do partido ao Estado Soviético (representação dos interesses mundiais do movimento comunista). Uma concepção marcial da luta de classes culmina, assim, num épico escatológico.

A partir do leninismo, ocorre um entrelaçamento entre ciência e política, que sustenta haver "um 'para si' de classe somente acessível à vanguarda iluminada" (LACLAU e MOUFFE, 2015, p. 122). e esta deveria se corporificar no partido, depois no Estado. Este passa a encarnar o 
representado (classe trabalhadora), falando, pensando, decidindo, agindo por ele, mas nem sempre com ele ou como ele havia sonhado. Na década de 1980, o declínio do socialismo, marcado pela queda do muro de Berlim (09/11/1989) e a dissolução da União das Repúblicas Socialistas Soviéticas (URSS), trouxe à tona crises econômicas e financeiras, altos índices de pobreza, combinados a regimes políticos totalitários.

Todavia, até a atualidade, a crítica marxista corrobora as lutas contra as desigualdades e injustiças do capitalismo, resultando em melhoria na qualidade de vida das populações, mais nos países capitalistas do que nos socialistas. Isto coloca em crise ambos os paradigmas. Ainda assim, o termo conservadorismo passou a caracterizar práticas e atitudes políticas em defesa da ordem econômica, política e social capitalista, da permanência do status quo das classes sociais dominantes (KIRK, 2016).

Os significados de democracia passam a transitar em torno desses dois modelos e das suas variações, marcadas por uma maior ou menor predominância dos princípios de mercado e diferentes níveis de intervenção Estatal, seja para garantir o atendimento às demandas das sociedades ou os privilégios de determinados grupos econômicos, políticos, burocráticos e outros, podendo recorrer a dispositivos de dominação mais ou menos repressivos. Assim, a democracia depende da correlação de forças entre Estado, mercado e sociedade civil. Portanto, organizações e movimentos contra as diferentes formas de subordinação, injustiças e desigualdades devem ser capazes de vislumbrar alternativas ao neoliberalismo, sem abdicar da democracia, que assegure liberdade de expressão, organização e manifestação política, cultural, religiosa, dentre outras. Nesse processo, a escola e o currículo cumprem papeis estratégicos. Como afirma Fernandez Enguita (2013), tanto as democracias quanto as ditaduras (de direita e de esquerda) utilizam a escola e o currículo para publicidade própria e para realização de suas finalidades. Para o autor, a diferença é que a primeira permite ser interpretada de diferentes formas e autoriza a oposição, com escassas restrições, enquanto a segunda não tolera a dissidência nem a diferença. Nesta perspectiva, tanto liberalismo quanto socialismo contêm elementos conservadores e/ou progressistas, em maior ou menor quantidade, mas a democracia plena será sempre uma impossibilidade. Aceitando esse entendimento, analisamos o conservadorismo nas políticas educacionais em três aspectos: manutenção do status quo capitalista; garantia de direito à cidadania; e direito à diferença étnicoracial, de gênero, de religião, de classe, geracional e outras. 


\section{Elementos progressistas e conservadores nas políticas educacionais no Brasil}

A partir da década de 1980, com o avanço da globalização, as saídas apontadas para os problemas sociais e educacionais embaçam ainda mais a significação/consolidação das democracias. Bauman (2000) argumenta que a república no Estado-nação perde seu poder de definir e promover o bem-estar de todos, passando tal função para o setor privado, progressivamente; a globalização da economia, das finanças e da informação minou o poder da república para garantir segurança à nação, enquanto ressurge e revigora um nacionalismo violento e desenfreado. Deste modo, os parâmetros e poderes que decidem sobre a condição humana são cada vez mais globalizados, enquanto "os instrumentos de controle e influência do cidadão, por mais poderosos que sejam, continuam limitados ao nível local” (BAUMAN, 2000, p. 172).

Nesse sentido, a reforma estatal no Brasil, a partir de 1990, inicialmente retomou orientações liberais de agências multilaterais como Banco Mundial, Fundo Monetário Internacional (FMI), Organização das Nações Unidas para a educação, a ciência e a cultura (Unesco), ainda que revestidas de discursos inovadores, como os da descentralização do poder e da assistência aos pobres (populismo). Essa reforma apontou para mudanças estruturantes, através da privatização do patrimônio público (empresas do setor energético, da telefonia de base, transporte, dentre outras), além da redefinição das funções do Estado (Emenda Constitucional 19/1998). O Estado, desde então, atua para garantir o realinhamento do capital, garantindo a sua conservação. Ball (2014, p. 26) avalia que esse realinhamento configura

o 'proto neoliberalismo', que é o projeto intelectual, moldado por Hayek e Friedman e outros teóricos econômicos e libertários, que foi fundamental a construção discursiva de uma crise política e econômica em torno do Estado de Bem-estar keynesiano e uma 'alternativa' para ele. Com raízes intelectuais rastreáveis até Adam Smith e David Ricardo, o catalisador para o renascimento da teoria do Estado econômico liberal foi a análise avassaladora de Frederick Hayek sobre coletivismo.

Embora o Estado no Brasil não se configurasse como de Bem-estar, sua participação era e ainda é relevante para todo o sistema. Nesse arranjo, a perspectiva neoliberal gerencialista foi decisiva no governo de Fernando H. Cardoso para reequilibrar a economia e para implementação de mecanismos de controle, a exemplo das prescrições curriculares e de sistemas de avaliação em larga escala, como o Exame Nacional da Educação Básica (Saeb), Exame Nacional do Ensino Médio (Enem) e do Provão/Exame Nacional de Cursos, substituído em 2004, pelo Exame Nacional de Desempenho do Estudante (Enade).

De modo análogo, o Sistema Nacional de Avaliação do Ensino Superior (Sinaes) não ocorreu apenas no que tange ao financiamento e a abertura para o mercado privado, mas via 
controle do currículo, consequentemente, dos resultados, ranqueando as instituições, certificando e corroborando para o fortalecimento da competição. O Estado privatiza, inteira ou parcialmente, os serviços públicos e assume prioritariamente sua função fiscal (GANDINI e RISCAL, 2002), que inclui arrecadação de recursos (taxas de impostos dentre as mais altas do mundo), avaliação, fiscalização e regulação dos sistemas, ferindo a autonomia das instituições educativas, dentre as quais as universidades.

Com isso, o Ministério da Educação (MEC) investe na Reforma da Educação Superior (BRASIL, 2002). Como resultado, o Brasil ampliou de 10 para 17\% o número de jovens de 18 a 24 anos no Ensino Superior. Neste nível havia em 2003 3.989.366 de alunos matriculados, passando para 7.839.765 em 2014 (crescimento de 96,5\%). Porém, 5.867.000 (74,9\%) estavam em Instituições de Ensino Superior (IES) privadas, e 1961.002 (25,1\%) em públicas. Além disto, 17,1\% das matrículas na graduação ocorrem na modalidade de Educação a Distância (EaD), sendo 89,6\% em IES privadas; quanto à área de cursos, predominam as licenciaturas (BRASIL, 2002).

Segundo Sguissardi (2014), no Brasil está ocorrendo uma intensa mercantilização do Ensino Superior, aspecto que tem sido omitido pelos discursos dos órgãos governamentais que disseminam a ideia de democratização do acesso. Sob esse aspecto, as políticas de Fernando Collor a Luís Inácio e Dilma Rousseff, representam um avanço de políticas (neo)conservadoras, que tem se intensificado em função da reestruturação do capital com características de financeirização. Torres et al (2004) reforçam esse entendimento, destacando que o Estado tem adotado ações como: investimento mínimo no combate ao analfabetismo e no financiamento da Educação Básica; abertura do setor, especificamente do Ensino Superior, para a participação de empresas estrangeiras, estimulando a utilização de novas tecnologias educacionais.

Todavia, como analisa Frigotto (2010), ainda que tenha havido uma continuidade nas políticas de Fernando H. Cardoso e Luís Inácio Lula da Silva, existem nestes diferenças significativas em favor das classes menos favorecidas, sendo a principal delas o trato com os movimentos sociais, especialmente antirracismo e homofobia. Outro diferencial diz respeito a agenda de luta e políticas afirmativas para o Ensino Superior como o sistema de reservas de vagas para as populações pobres, negras, com deficiência e oriundas de escolas públicas, que tem implicações severas sobre o fracasso/sucesso acadêmico.

Os parcos avanços obtidos, contudo, vêm tendo retrocessos desde o início do segundo mandato de Dilma Rousseff (01/2015), quando foram cortados aproximadamente 10 bilhões das verbas da educação, suspendendo ou extinguindo importantes programas. Outras tendências tem 
sido a desprofissionalização do trabalho docente, expressos em oferta de vagas com remuneração inferior a praticada com os efetivos e sem exigência de formação pedagógica (serviço prestado, voluntário, substituto); a precarização das condições de trabalho docente; e o ensino técnicoprofissional (Institutos Federais de Educação e Pronatec).

As medidas adotadas pelo governante atual, Michel Temer, após o impeachment, sinalizam com novos retrocessos, pois as "medidas econômicas de austeridade", ainda que necessárias para reequilibrar a economia, tendem a impor sacrifícios e restrição de direitos. Exemplo disto, é o Projeto de Emenda Constitucional 55/2016, que propõe restrição e até congelamento de investimento em diversas áreas, inclusive saúde e educação. Outro exemplo é a Medida Provisória no 746/2016 (BRASIL, 2016), que altera o art. 61 da LDB/1996 para permitir que "pessoas com notório saber", sem exigência de formação pedagógica, possa atuar como docente na área de formação "Técnica e profissional", no Ensino Médio, o que tende a induzir os/as jovens mais pobres a inserção profissional em detrimento da continuidade dos estudos.

Reforçando a tendência à regulação do currículo, encontra-se a elaboração da Base Nacional Comum Curricular (BNCC), que deverá ser aprovada até junho de 2017 e o Projeto de Lei Escola Sem Partido, que ameaça a liberdade de expressão dos/as professores/as, de modo semelhante aos Atos Institucionais outorgados durante a Ditadura Militar. Como sinaliza Apple (2003), o controle dos gastos públicos, a ênfase na competitividade, a formação de consumidores e de força de trabalho, o controle do conhecimento, através dos currículos padronizados, o reavivamento das tradições ocidentais, do patriotismo, a busca incessante pela cultura e ideologias comuns são faces do realinhamento do conservadorismo liberal.

\section{A reconstrução do currículo de Pedagogia: situando o objeto de estudo}

A reconstrução do PPC, portanto, também do currículo, que se iniciou com a eleição dos membros do Núcleo Docente Estruturante (NDE), em setembro de 2014, até a entrega do projeto à Pró-reitoria de Graduação (Prograd), em 30/08/2016. No decorrer desse processo, o NDE promoveu as seguintes ações: reuniões com professores e alunos/as de todas as turmas, em maio de 2014; autoavaliação do curso, de outubro a dezembro 2014, da qual participaram 13 professoras e 306 alunos/as; um curso de extensão, “Avaliação para reconstrução do PPC de Pedagogia da UEPB”, desenvolvido de março a maio de 2015 para sistematizar os dados da autoavaliação, do qual participaram 11 estudantes; o Seminário Nacional de Pedagogia (Senped), realizado de 3 a 5 de junho de 2015. Posteriormente, entre os dias 14, 15 e 16 de dezembro do referido ano, ao retornar de uma greve que perdurou por cinco meses, as atividades do NDE foram retomadas, momento em 
que os professores discutiram dados parciais, apresentados pelo NDE, da autoavaliação realizada em 2014, identificando e definindo problemas prioritários, como: excessivo número de disciplinas por semestre; não cumprimento dos horários de aulas e falta de intervalo; aumento da carga-horária definida no novo Regimento (UEPB, 2015). Em 17/03/2016 as discussões foram retomadas, quando a presidente do NDE informou que os dados da autoavaliação não seriam apresentados nem discutidos com os alunos; além disso, os estudantes não participariam das decisões acerca das mudanças curriculares, pois a Prograd estabelecera o dia 30/04/2016 para entrega dos PPC e o tempo havia se tornado exíguo.

A pesquisa em foco seguiu o percurso do PPC com as seguintes etapas: 1) Observação e registro de reuniões e assembleias voltadas à reconstrução do PPC; 2) Aplicação de questionário a docentes e estudantes dos turnos matinal e noturno; 4) Análise de textos/documentos, incluindo mensagens do Whatsapp do Departamento de Educação; 5) Sistematização e análise do material empírico. Recorremos à observação participante, com recurso de questionário e análise de textos/documentos. Como analisa Mattos (2011), a observação participante se constitui num método científico, que exige uma atenção ampliada e particular acerca do objeto de estudo, o que implica em determinadas dificuldades porque o relativismo cultural do participante pode comprometer a dialética entre objetivação e observação do objeto. Portanto, tivemos como preocupação, evitar julgamentos finais e compreender os eventos como eles acontecem do ponto de vista dos vários atores e através dos seus valores (MATTOS, 2011).

Nesse processo, textos/documentos se constituem em material empírico que não devem ser fetichizdos, mas problematizados, cruzados e confrontados com outras fontes. Para Corsetti (2006), isto envolve seleção, tratamento e interpretação das informações, com o objetivo de produzir novos sentidos. Assim, consideramos como documentos, textos jurídico-normativos, planos/projetos curriculares, registros de entrevista, questionários e mensagens de redes sociais virtuais como Whatsapp e outros que ajudam na recomposição e na análise dos sentidos/significações de democracia.

O campo empírico foi o Curso de Pedagogia (UEPB/campus I). Desde 1969 quando começou a funcionar, o curso sofreu várias modificações, sendo as mais recentes instituídas com o PPC de 2009, quando foram extintas as habilitações de Supervisão Escolar e Orientação Educacional, seguindo determinações do Conselho Nacional de Educação (CNE) (BRASIL, 2006). $\mathrm{O}$ curso destina-se à formação de docentes para a Educação Infantil e Anos Iniciais do Ensino Fundamental $\left(1^{\circ}\right.$ a $\left.5^{\circ}\right)$, bem como para gestão pedagógica e escolar, de redes de ensino e de instituições afins (PARAÍBA, 2009). 
O curso possui 43 professores efetivos e nove professores substitutos. Dentre os efetivos, 14 são mestres (32\%), 25 são doutores (58 \%) e quatro estão cursando doutorado (10\%). As quatro gestoras têm formação em nível de doutorado e foram eleitas pela comunidade acadêmica em 2015. O corpo discente se constitui de 628 estudantes. Logo, os sujeitos da pesquisa são 6 profissionais e 13 estudantes. Os profissionais foram identificados como: Coordenadora da Prograd, responsável por orientar os trabalhos em todos os cursos; Professora membro do NDE; e os Professores do curso, referidos por 1, 2, 3 e 4. As docentes têm bastante experiência no Ensino Superior - apenas uma tem menos de dois anos de atuação, as demais atuam a mais de oito anos. Das 6 docentes, 5 possuem formação em nível de doutorado. A Coordenadora da Prograd e a Professora membro do NDE exercem também funções administrativas. Quanto aos/às estudantes (referidos como 1,2 e 3 do sexo masculino - e 1,2,3,4,5,6,7,8,9 e 10 - do feminino), temos o seguinte: a maioria (nove) destes alunos cursou no máximo 5 períodos (metade do curso); sete estudam no noturno; três trabalham exercendo funções alheias à educação; duas exercem função docente, sendo uma delas voluntária do PME. ${ }^{3}$ Em geral o nível econômico das famílias dos/as estudantes de Pedagogia fica dentre os mais baixos, quando comparados a outros cursos. No curso pesquisado, 79,3\% das famílias dos/as estudantes tinham renda até três salários mínimos ( $\mathrm{R} \$ 2.172,00)$ e apenas 0,8\% acima de dez (BRASIL, 2014). Comparando dados nacionais, apenas 5\% das famílias têm renda acima de dez salários, enquanto Medicina chega a 44\%, Odontologia 28\%, Direito $24 \%$ e Psicologia 16\% (RISTOFF, 2014). Portanto, necessitam trabalhar desde muito jovens ou necessitam de programas assistenciais e de bolsas de estudo (pesquisa, extensão e monitoria). Uma grande parcela também necessita de transportes intermunicipais diariamente, pois residentes em cidades circunvizinhas.

\section{DEMOCRACIA QUE TEMOS/QUEREMOS: REFLEXÕES A PARTIR DO PROCESSO DE RECONSTRUÇÃO DO CURRÍCULO DE PEDAGOGIA}

\section{Reflexões a partir de significados expressos por profissionais}

A partir do reconhecimento de que as políticas educacionais tem representado um avanço do conservadorismo no sentido do realinhamento do neoliberalismo, da restrição de direitos à cidadania e à diferença, objetivamos, nesta seção, analisar significados de democracia recorrentes durante a reconstrução do PPC de Pedagogia, (UEPB/campus I) em textos/discursos de docentes e

\footnotetext{
${ }^{3}$ Através deste Programa, as secretarias “contratam" pessoas das comunidades e/ou estudantes para ministrar oficinas pedagógicas em diversos campos do conhecimento (letramento, reforço, Matemática, esporte, arte e outros), pagandolhes R\$ 80,00 por turma ao mês em forma de ajuda de custo. Cada pessoa pode trabalhar em até cinco turmas.
} 
discentes. Interessa-nos analisar tais significações como formas de reação às políticas conservadoras. Como assevera Ball (2014, p. 13),

Nós pouco ainda sabemos sobre 'o que realmente está acontecendo'. Estamos diante de decidir em 'condições de indecisão' (DERRIDA, 1996), bem como tomar um posicionamento em tudo isso, sendo cúmplices, imbricados e comprometidos. Neoliberalismo não está 'lá fora'.

Encontramo-nos todos enredados nas tramas da globalização, do neoliberalismo e da democracia possível nessa trama. Como afirma Laclau (2011), o universal não tem um conteúdo concreto próprio (que o enclausure em si próprio), mas é o horizonte sempre móvel que resulta de uma cadeia indefinida de demandas equivalentes. Assim, parece ser que a universalidade é incomensurável com qualquer particularidade e, não obstante, não pode existir fora do particular. A insolubilidade entre universal (global, nacional) e particular (local) é, para Laclau, precondição para a democracia. É porque diferentes grupos competem entre si para dar uma função de representação aos seus particularismos que a democracia se faz possível (hegemônica), ainda que contingencialmente (LACLAU, 2011). Portanto, é também no interior das instituições que as disputas, dissonâncias, acordos, articulações vão se firmando. Assim, o entrelaçamento entre a conjuntura nacional e a reconstrução do PPC tornou-se inevitável, bem como as disputas pelos sentidos de democracia. Foi, então, nesse entrelaçamento que se realizaram também as reuniões do NDE e as reflexões decorrentes da pesquisa em foco.

Em princípio, questionamos a respeito da importância do PPC e da sua reconstrução. As 6 docentes participantes da pesquisa ratificaram sua importância, afirmando que o PPC se constitui em documento de identidade do curso, no qual se definem as condições de funcionamentos do curso, o perfil dos/as estudantes, os objetivos, a organização curricular, os princípios orientadores e outros aspectos. Nos termos da professora membro do NDE, “o PPC é muito importante; aliás, representa a essência do curso, pois nele estão definidas as concepções filosóficas e teóricometodológicas que movem os sujeitos”. Em geral, as professoras alegam ser necessária a reconstrução do PPC, uma vez que ele não é eterno e deve acompanhar as dinâmicas e mudanças socioeconômicas e científico-tecnológicas da sociedade. Em relação à questão sobre os significados de democracia, obtivemos as respostas apresentadas na íntegra, a seguir:

A democracia é um sistema em que todos os cidadãos, a despeito de suas diferenças, têm o direito de escolher seus representantes. Os cidadãos têm o direito de decidir sobre quem tomará decisões em seu nome, ou seja, quem os representa dentro do grupo que faz a gestão do que é coletivo. A democracia é o Poder da Maioria (Coordenadora Prograd).

Forma de governança exercida com o povo, ou pela escolha do povo, representando os seus interesses (Representante NDE). 
Um modo de relação entre as pessoas, que garante a liberdade de exposição de diferentes pontos de vista e de discussão, a fim de se chegar a consensos (Professora 1).

Democracia significa ter deveres a cumprir e, consequentemente, a garantia de que os direitos serão respeitados na mesma proporcionalidade. Além disso, significa a mudança de postura quando algo não dá certo, a liberdade de opinião, desde que não agrida o outro e, sobretudo, a convivência e aceitação da diversidade (Professora 2).

Garantia dos direitos civis, cumprimento das obrigações e liberdade de expressão, sem que esta não seja utilizada como mecanismo ofensivo aos demais integrantes do grupo social do qual se participa (Professora 3).

Este é um termo polissêmico e, portanto, a este são dispensados significações diversas. Pode-se signicá-lo como igualdade de direitos e oportunidades, direito de ouvir e ser ouvido, construção de subjetividades combativas. Há ainda que se considerar as influências dos grupos que defendem tal termo, uma vez que ainda que possam apresentar os mesmos significantes, estes são encarnados de significados, por vezes, divergentes (Professora 4).

Levando em consideração os significados apresentados na seção 2 deste artigo, inferimos que as respostas se coadunam com os ideais de democracia liberal, nas quais o sistema de governança e a convivência cotidiana deve garantir representação, direitos civis (cidadania), dentre os quais o de liberdade de expressão, sem descuidar das obrigações de cada cidadão. Há nas respostas ausência de conflitos, de embates, de competição, bem como de desonestidade, de jogo de interesses comum às democracias reais, como a brasileira. Tal ausência apenas faz sentido nas utopias, onde determinadas variáveis são controladas ou evitadas. Como assinala Fernandez Enguita (2013, 67), essas representações amenizam “o autoritarismo e a burocracia das administrações, o partidarismo, o eleitoreirismo dos políticos e, sobretudo, o egoísmo dos consumidores, a ânsia de lucro das empresas e o neoliberalismo que nos invade".

Foi no Whatsapp Departamento de Educação que tais paradoxos se revelaram através de posts acerca do impeachment da ex-presidente, Dilma Rousseff, quando se tornaram recorrentes atividades classificadas como sendo "em defesa da democracia", a exemplo de visita às salas de aula, panfletagens, palestras, cartazes, faixas, manifestações do Movimento Sem Terra (MST) e outros, dentro ou nas imediações do Centro de Integração de Aulas (CIAC), onde funciona o curso em questão, geralmente promovidos por sindicatos.

Essas atividades eram divulgadas, principalmente, em redes sociais, tais como o Whatsapp Departamento de Educação e ADUEPB - Resistência e Luta. Esse Whatsapp do Departamento foi criado em 20/11/2015 pela coordenadora adjunta do Curso, atendendo a reivindicações de docentes, apresentadas em assembleias departamentais, quanto à necessidade de ampliar os canais de 
comunicação e informação. Analisamos mensagens de 02/03/2016 a 23/04/2016, veiculadas por professores. Das 264 mensagens contabilizadas, identificamos os assuntos a seguir no Quadro 1.

Quadro 1. Assuntos das mensagens do Whatsapp Departamento de Educação

\begin{tabular}{|l|l|}
\hline ASSUNTOS & QUANTIDADE \\
\hline $\begin{array}{l}\text { Partido dos Trabalhadores e impeachment da Presidente Dilma } \\
\text { Rousseff }\end{array}$ & 97 \\
\hline Mensagens religiosas (católicas) & 39 \\
\hline Mensagens de pesar pelo falecimentos de parentes de professores & 38 \\
\hline Informes do Departamento de Educação & 35 \\
\hline Saudações, otimismo e outros & 33 \\
\hline Informes da ADUEPB & 12 \\
\hline Aviso/alerta contra violência & 4 \\
\hline Questões educacionais & 6 \\
\hline Total de mensagens & 264 \\
\hline
\end{tabular}

Fonte: As autoras, a partir dos dados do Whatsapp Departamento de Educação.

A leitura das mensagens revelou que a maioria delas é de apoio/defesa ao Partido dos Trabalhadores (PT) e contra o impeachment. As 97 mensagens foram postadas por quatro professores 1e apenas quatro tiveram os conteúdos contestados. ${ }^{4} \mathrm{O}$ conteúdo das mensagens foi categorizado da seguinte forma: i) Elogios e apoio ao ex-presidente Luiz Inácio Lula da Silva, a exemplo de: “Todo apoio a Lula. Ele representa o que de melhor há no Brasil; O último país das Américas a abolir a escravidão, hoje quer esmagar Lula, o filho mais legítimo deste país; ii) Defesa da presidente Dilma Rousseff e/ou contrários ao impeachment (por exemplo, áudio de M. Chauí e texto da secretaria executiva do Conselho Latino-americano de Ciências Sociais - CLACSO); iii) Denúncias e ofensas ao juiz Sérgio Moro, ao judiciário e à Polícia Federal. Nas mensagens, a palavra democracia aparece reiteradamente, porém sempre como prerrogativa do PT, de Dilma e de Lula, como se esses sujeitos a encarnassem, como se o Estado democrático fosse prerrogativa desses atores e não uma construção social.

Chamou-nos a atenção o silenciamento quanto às acusações que pairavam sobre corrupção envolvendo a Petrobrás, empreiteiras e membros do alto escalão dos governos petistas; contabilidade fraudulenta (caixa 2) nas campanhas; estelionato político para eleger Dilma Rousseff, que logo após sua posse obteve altos índices de reprovação; desmonte de sofisticados esquemas de

\footnotetext{
${ }^{4}$ As contestações foram feitas por uma das autoras deste artigo, objetivando coletar dados para pesquisa (observação participante). Foram colocados prints de um grupo de Facebook, nomeado UEPB Sem Censura, de alunos criticando professores por manifestações do MST em outro campus. Em resposta à contestação foram colocados vídeos, fotos e textos criticado a "direita", elogiando Lula, Dilma e José Mujica, dentre outros.
} 
corrupção e a repatriação de dinheiro de corrupção, amplamente divulgados em outras mídias e espaços.

Como afirma Sales Júnior (2008, p. 162), “todo discurso é uma tentativa de dominar o campo da discursividade, deter o fluxo da diferença, construir um centro, dizer a verdade do social”. Não sem razão, a "narrativa do golpe" e da "ruptura democrática" logrou êxito no campo discursivo em análise, hegemonizando-se, contudo, as razões dos "silenciamentos" (consenso, convencimento, coerção) são questionáveis, em função das relações de poder e dominação que as ensejam. É prudente pensar que, tão autoritária quanto a "Escola sem Partido", que pretende impedir o acesso às diferentes ideologias, é a "Escola de Pensamento Único", que pretende permitir acesso a apenas uma ideologia. Como analisa Laclau (2011), quando um particularismo se afirmar numa mera relação diferencial com as outros, sancionará o status quo das relações de poder entre os grupos, sendo este o fundamento de toda hegemonia autoritária, seja de direita ou de esquerda.

Quanto ao fato de o PPC de Pedagogia se configurar ou não como processo democrático, a Professora membro do NDE e três professoras alegaram que sim, pois o processo foi coordenado pelo NDE, cujos membros são definidos por eleição dos que se candidatam espontaneamente; também porque todos/as os/as professores/as são convocados/as, quem não participa o faz por decisão própria. A coordenadora da Prograd afirmou não poder julgar, uma vez que não conhece o processo internamente. Já a Professora 4 advoga "que havia inicialmente a pretensão de que o referido se constituisse enquanto processo democrático, todavia, isto não se confirmou. Na prática, um grupo decide e os demais participantes das assembleias apenas ratificam tais decisões”.

Quando questionadas sobre quem seriam os responsáveis para promover as mudanças necessárias ao currículo de Pedagogia, a resposta das docentes foi a de que a responsabilidade é coletiva, devendo envolver a coordenação, os grupos da comunidade acadêmica e o Colegiado do Curso. Nem a Professora membro do NDE, também chefe do Departamento, à época, nem as professoras consideraram os/as estudantes como legítimos membros da comunidade acadêmica. A Coordenadora da Prograd respondeu que "o NDE deve consultar a comunidade acadêmica, tanto alunos, quanto técnicos e docentes para fazerem as propostas de mudanças”. Sem a participação de estudantes, na assembleia do dia 16/06/2016 foi aprovada a retirada do currículo das disciplinas Ética, Epistemologia e Estágio em Gestão Educacional I e a criação de nove disciplinas, dentre elas, Educação para o campo, Educação Infantil II, Currículo e metodologia para a Educação Infantil. Segundo o NDE, a não participação dos/as estudantes deveu-se ao fato de que após a greve (junho a novembro de 2015), o tempo ficou exíguo, mediante as exigências da Prograd para conclusão do PPC, também porque, durante a greve, dois membros do NDE renunciaram às suas funções, 
exigindo uma reestruturação do Núcleo. Isto pode justificar a exclusão dos/as estudantes, mas não torna o processo democrático, inclusive porque eles/as forma mobilizados e mostraram-se interessados em participar.

\section{Reflexões a partir de significados de democracia expressos por estudantes}

No tocante aos significados de democracia, as respostas dos discentes se assemelham ao das docentes, apontando para a perspectiva liberal (vontade da maioria, garantia de direitos, liberdade de expressão e outros). Nenhum/a dos respondentes fez crítica ao capitalismo ou menção ao socialismo. Todavia, quando questionados se o processo de reconstrução do PPC havia se configurado como democrático, os/as alunos/as apresentaram as respostas do Quadro 2.

Quadro 2: Respostas de discentes sobre a reconstrução do PPC e as causas apontadas

\begin{tabular}{|c|c|}
\hline Aluno 1 & $\begin{array}{l}\text { NÃO. Porque não atinge as principais necessidades dos discentes no que se refere à } \\
\text { participação de sua construção. }\end{array}$ \\
\hline Aluno 2 & Não é possível responder tal pergunta, pois ao aluno nada é divulgado. \\
\hline Aluno 3 & NÃO. Porque não existe participação dos alunos e se existe se restringe a alguns \\
\hline Aluna 1 & $\begin{array}{l}\text { NÃO. Embora estejamos sabendo da reconstrução do PPC, apenas alguns alunos } \\
\text { responderam os questionários e isso não é um processo democrático. }\end{array}$ \\
\hline Aluna 2 & NÃO. Porque não levam em consideração a opinião dos alunos para a melhoria do curso \\
\hline Aluna 3 & $\begin{array}{l}\text { NÃO. Pois os questionários que o departamento de pedagogia respondeu não foram } \\
\text { levados em conta }\end{array}$ \\
\hline Aluna 4 & NÃO. Porque nós alunos não participamos ativamente da construção \\
\hline Aluna 5 & $\begin{array}{l}\text { NÃO. Em nenhum momento nós alunos somos convidados a participar e opinar em } \\
\text { nada. }\end{array}$ \\
\hline Aluna 6 & Não respondeu \\
\hline Aluna 7 & $\begin{array}{l}\text { NÃO. Pois o conselho do curso toma e aprova uma série de medidas sem consultar o } \\
\text { graduando, uma vez que os mesmos são os maiores interessados. }\end{array}$ \\
\hline Aluna 8 & $\begin{array}{l}\text { NÃO, porque o corpo discente não tem sido incluído nas discussões e nos debates sobre } \\
\text { o mesmo. }\end{array}$ \\
\hline Aluna 9 & $\begin{array}{l}\text { NÃO. Pois é necessária a participação de todos os envolvidos no PPC, caso este que não } \\
\text { ocorre nos cursos em gerais na UEPB }\end{array}$ \\
\hline Aluna 10 & NÃO. Por que não se procura saber e ouvir o que o estudante pensa do projeto \\
\hline
\end{tabular}

Fonte: As autoras, a partir dos dados dos questionários.

O fato preocupante é que dos 13 participantes da pesquisa, deze afirmam, categoricamente, que o processo não foi democrático e um não respondeu. Ainda que a exclusão dos estudantes tenha se dado em função do tempo exíguo, estes emergem como o outro do processo, o diferente, o excluído. Faltou a compreensão de que "a educação, como relação intersubjetiva, é um processo que deve permitir que um sujeito singular emerja, não apenas como reconhecimento, mas como ação que cria sentidos novos, na enunciação do novo, na produção da diferença em si” (MACEDO, 
2014, p. 100). Perdeu-se a oportunidade de maior diálogo com esses sujeitos e de proporcionar-lhe participação nas decisões que os afetam diretamente.

Sobre as mudanças que propuseram para o currículo, entendemos que uma foi atendida (Aluna 5): ampliação da carga horária da disciplina Língua Brasileira de Sinais (Libras). Outra foi atendida parcialmente (Aluno 3), pois foi criada a disciplina Produção Textual II e ele havia proposto a criação de Língua Portuguesa. Sobre os responsáveis pelas mudanças, afirmaram ser o reitor, as coordenadoras, professores/as, NDE, gestores/as. O Aluno 2 afirmou: "Não sou capaz de responder, pois há uma confusão e nada é esclarecido aos alunos”. Já a Aluna 3 afirma que são "os alunos, mas na instituição, aluno e nada é a mesma coisa". Isto é lamentável, pois deveriam ter consciência dos seus direitos e responsabilidades com a qualidade do curso. Com relação às contribuições de cada aluno/a para reivindicação e efetivação das mudanças necessárias, apenas as Alunas 1 e 4 se percebem contribuindo, embora de forma muito limitada. Já as Alunas 5 e 8 se colocam à disposição para participar, mas parecem esperar que esta participação seja delegada por quem coordena o processo.

Enquanto as professoras legitimaram os discursos em defesa da democracia naturalizaram a não participação dos/as estudantes, estes/as entenderam a participação democrática como concessão. Há um vazio no sentido do político como espaço de significação, de luta, de enfrentamento e de construção da democracia nos diferentes âmbitos do social, dentre os quais, educação e currículo. Contudo, como analisa Lopes (2014, p. 58), "é no processo político que inventamos os significados de justiça social e de democracia, e tantas outras bandeiras, e mesmo o que entendemos por social a ser transformado". Nesse sentido, a luta se desenvolve em diferentes espaços e tempos de produção de textos e discursos curriculares, pois estes também podem interromper e desconstruir instituições e tradições, produzindo novos modos políticos de interpretar, de agir, de constituir-se enquanto identidade democrática e democratizante.

Com relação aos/às alunos/as, encontramos no Whatsapp Departamento de Educação mensagens, fotografias e prints, que eram comentários de alunos sobre um evento da Jornada de Manifestações Universitárias do MST, ocorrido no dia 20/04/2016 em outro campus. Eram mensagens, tais como:

Canalhas em ação. Nada mais que isso.

Chame a polícia.

Pressão da UEPB por parte dos professores é tão grande que, em seminários, minhas notas são as piores... kkkk. Posso fazer um show de apresentação, ou não, que dá na mesma. Isso que dar ser reacionário em covil de lobos... kkkk 
MST acaba de invadir a universidade, atendendo ao chamado de professores para fazerem ato "contra o golpe". O que você acha da atitude desses professores.

Acho que também são uns golpistas!!!

Tem professor aí que só aparece em manifestação porque aula, que é bom, nunca deu.

Lá ia eu, de cabeça baixa ao ver tanta gente de vermelho aos gritos, como se estivessem surtadas. Calado me mantive e de olhar rasteiro continuei em direção à minha sala, no entanto, quando chego, me deparo com um circo, no sentido literal da palavra.

$\mathrm{O}$ (a) professor(a) que fez os posts dizia-se preocupada com os riscos que os membros do MST corriam com aqueles alunos/as; afirmava que a manifestação do MST havia sido ordeira e cidadã; e parabenizava os professores organizadores do evento. Essa jornada aconteceu pelas universidades sem que qualquer violência mais grave tenha sido noticiada. Evento semelhante também aconteceu no CIAC, no mesmo período.

Esses prints foram extraídos de um grupo de Facebook nomeado UEPB Sem Censura. Em entrevista, um dos criadores deste grupo informou que o grupo havia sido criado porque, em outro grupo de estudantes da UEPB aconteciam debates acirrados sobre partidos, impeachment, capitalismo, socialismo e outros temas. Segundo o entrevistado, era um grupo de alunos de "esquerda", que quando tinham suas mensagens contestadas removiam os opositores. Então, alguns dos alunos "removidos" resolveram criar um grupo, no qual as pessoas (não apenas alunos) pudessem postar o que quisessem, sem ser removidas. Já no Facebook citado, a administradora do grupo apelou para que determinados alunos não fizessem posts agressivos e inconvenientes.

Os relatos revelam a dispersão dos sentidos atribuídos a democracia, bem como às posições dos sujeitos. Como assinalam Laclau e Mouffe (2015), a afirmação do caráter discursivo de toda posição de sujeito foi relacionada à rejeição da noção do sujeito como totalidade originária e fundante. Assim, o momento analítico que prevaleceu foi o da dispersão, testotalização ou descentramento de certas posições com respeito a outras. Portanto, o processo de significação continua em aberto, tanto é que, na aos prints dos estudantes, encontramos outros que criticavam as democracias liberais (direita conservadora, arrogante e outros adjetivos) e em defesa do socialismo, dentre eles, fragmentos de um discurso do ex-presidente do Uruguai, José Mujica, no qual criticava a democracia liberal e defendia que a esquerda latino-americana necessitava se reinventar.

\section{CONSIDERAÇÕES FINAIS}

Encerrada a etapa da reconstrução do PPC, que passa a depender da aprovação do Conselho Universitário (Consuni/UEPB) e do Conselho Estadual de Educação, só poderão ser feitas pequenas 
modificações para atender às exigências de órgãos consultivos/deliberativos. Significa, portanto, que o processo se encerra sem a participação dos estudantes.

Retornando às duas questões que conduziram a pesquisa, concluímos que, com relação a primeira, prevaleceram os significados associados ao liberalismo nas respostas aos questionários, mas a dicotomia, liberalismo/socialismo esteve presente, de forma marcante, em outras narrativas, tais como das redes sociais virtuais e das atividades militantes. Com relação à segunda, pudemos evidenciar que houve exclusão dos/as alunos/as, sob a alegação do NDE de que, após a greve, o tempo havia se tornado exíguo, mediante as exigências da Prograd para conclusão do documento. Porém, ainda que a justificativa seja plausível, o processo não foi democrático se não incluiu nas decisões a maioria dos interessados (628 estudantes) nas decisões, nem mesmo por representação.

Por fim, concluímos que as políticas educacionais e curriculares, em especial, sinalizam com o realinhamento do neoliberalismo, que tem como imperativo privatização dos serviços; redução de direitos civis que afetam de forma mais insidiosa às populações historicamente marcadas por formas de discriminação negativa (machismo, homofobia, racismo, antissemitismo, xenofobia e outras), que geram e/ou justificam injustiças sociais de diversas ordens. Nesse sentido, há um avanço do conservadorismo, porém, assim como o significante democracia, seus horizontes também não são fixados em definitivo, podendo ser deslocado em função da correlação de forças sociais. Ambos são construções históricas e políticas. Com relação à democracia e às identidades dos sujeitos da democracia, é importante reconhecer os avanços dos modelos liberal e socialista, mas também enfrentar as distorções, incongruências e injustiças sociais, ou seja, é necessário enfrentar as hegemonias autoritárias e reinventar o político (instituinte). 


\section{REFERÊNCIAS}

APPLE, M. Educação à direita. São Paulo: Cortez, 2003.

BALL, S. Educação global S. A. novas redes políticas e o imaginário neoliberal. Trad.: Janete Bridon. Ponta Grosa: UEPG, 2014.

BAUMAN, Z. Em busca da política. Trad.: Marcos Penchel. Rio de Janeiro: Zahar: 2000.

BRASIL. Ministério da Educação. Reafirmando princípios e consolidando diretrizes da reforma da educação superior: Documento II. Brasília: MEC, 2002.

Ministério da Educação. Conselho Nacional de Educação. Resolução n. 1, 15 maio 2006. Institui Diretrizes Curriculares Nacionais para o Curso de Graduação em Pedagogia, licenciatura. Brasília: MEC/CNE, 2006.

Instituto Nacional de Estudos e Pesquisas Educacionais Anísio Teixeira. Exame Nacional de Desempenho de Estudantes. Brasília: INEP, 2014.

Ministério de Educação. Medida Provisória 746, 22 set. 2016. Institui a Política de Fomento à Implementação de Escolas de Ensino Médio em Tempo Integral, altera a Lei 9.394, 20 dez. 1996. Brasília: MEC, $2016 a$.

Senado Federal. Proposta de Emenda Constitucional 55, 9 nov. 216. Altera o Ato das Disposições Constitucionais Transitórias, para instituir o Novo Regime Fiscal. Brasília: Senado Federal, $2016 \mathrm{~b}$.

CORSETTI, B. A análise documental no contexto da metodologia qualitativa. In: UNIrevista, v. 1, n. 1, p. 32-46, 2006. Disp.: 〈http://www.scielo.br/scielo.php?script>. Acesso: 20 maio 2016.

FACEBOOK UEPB SEM CENSURA. Disp.: 〈https://www.facebook.com/groups/GrupoUEPB/?fref=ts>. Acesso: 25 ago. 2015.

GANDINI, R.P.; RISCAL, S.A. A gestão da educação como setor público não estatal e a transição para o estado fiscal. In: OLIVEIRA, D.A.; ROSAR, M.F. (Orgs.). Política e gestão da educação. Belo Horizonte: Autêntica, 2002. p. 3958.

FERNANDES ENGUINTA, M. As forças em ação: Sociedade, economia e currículo. In: SACRISTÁN, José Gimeno. (Org.). Saberes e incertezas sobre o currículo. Porto Alegre: Penso, 2013.

LACLAU, E. Emancipação e diferença. Coordenação e revisão técnica de Alice C. Lopes e Elizabeth Macedo. Rio de Janeiro: EdUERJ, 2011.

; MOUFF, C. Hegemonia e estratégia socialista. Trad.: Joanildo Burity; Josias de Paula; Aécio Amaral. São Paulo: Intermeios, 2015.

LOPES, A. C. Ainda é possível um currículo político? In: LOPES, A.C.; DE ALBA, A. (ORGS.). Diálogos entre Brasil e México. Rio de Janeiro: EdUERJ, 2014.

LOPES, A.C.; MACEDO, E. Teorias de currículo. São Paulo: Cortez, 2011.

KIRK, R. The conservative mind. Washington DC: Gateway Editions, 1986. Disp.: <www.kirkcenter.org/index.php>. Acesso: 29 set. 2016

MACEDO, E. Currículo, cultura e diferença. In: LOPES, A.C.; ALBA, A. (Orgs.). Diálogos curriculares entre Brasil e México. Rio de Janeiro: EDUERJ, 2014. p. 83-104.

MARX, K.; ENGELS, F. Manifesto comunista. Versão para ebook. Ridendo Casting Mores. Disp.: 〈www.jahr.org . Acesso: 15 set. 2016.

MATTOS, C. G. A abordagem etnográfica na investigação científica. In: MATTOS, C.G.; CASTRO, P.A. (Orgs.). Etnografia e educação. Campina Grande, PB: EDEPB, 2011. p. 49-84.

PARAÍBA. Universidade Estadual da Paraíba (UEPB). Projeto Político Pedagógico do Curso de Pedagogia. Campina Grande/PB. 2009.

QUEIROZ, Danielle Teixeira et al. Observação participante na pesquisa qualitativa. In: Revista de EnfermagemUERJ, Rio de Janeiro, n. 15, v. 2, 276-83 abr./jun. 2007. 
RISTOFF, D. O novo perfil do campus brasileiro: uma análise do perfil socioeconômico do estudante de graduação. In: Revista de Avaliação, Campinas; Sorocaba, SP, v. 19, n. 3, p. 723-747, nov. 2014.

SALES JÚNIOR, R. Laclau e Foucault: desconstrução e genealogia. In: RODRIGUES, L. P.; MENDONÇA, D. de (Orgs.). Pós-estruturalismo e teoria do discurso. Porto Alegre: EDIPUCRS, 2008. Cap. 8, p. 145-157.

SGUISSARDI, V. Educação superior no Brasil: democratização ou massificação mercantil? Educação e Sociedade., Campinas, v. 36, n. 133, p. 867-889, out.-dez. 2015

TORRES, C. M. et al. A contrarreforma da educação superior: uma análise do ANDES-SN das principais iniciativas do governo Lula da Silva. Brasília: ANDES, 2004.

\section{RESUMO}

Reconhecendo que as políticas educacionais mais recentes refletem um avanço do conservadorismo quando promove o realinhamento do neoliberalismo, afetando de forma mais insidiosa as identidades historicamente discriminadas em função de diferenças culturais, este artigo analisa o processo de reconstrução do currículo de Pedagogia (UEPB/campus I), enfatizando significados de democracia que o permearam. Para tanto, recorre ao método da observação participante, concluindo que, ao não garantir a participação dos/as estudantes nas decisões, a reconstrução não se constituiu em processo democrático, reforçando práticas discursivas dissonantes com os discursos recorrentes na academia e com os objetivos do projeto de reconstrução.

Palavras-chave: Pedagogia. Currículo. Democracia.

\section{DEMOCRACY THAT WE HAVE / WANT, TOWARDS CONSERVATISM IN EDUCATIONAL POLICIES}

\section{ABSTRACT}

Recognizing that the most recent educational policies reflect conservatism advance when promoting neoliberalism realignment, which affects more insidiously historically discriminated identities per cultural differences, this paper analyzes Pedagogy curriculum reformulation process at State University of Paraíba (campus I, Campina Grande, Brazil). It emphasizes democracy meanings that permeated such process Therefore, this study performs participant observation method. It is concluded that, by failing to ensure students' participation in decisions, curriculum reformulation did not constitute a democratic process. Besides, it reinforces dissonant discursive practices recurrent in the Academy and with reconstruction project goals.

Keywords: Pedagogy. Curriculum. Democracy. 